\title{
Sepsis and Pediatric Acute Respiratory Distress Syndrome
}

\author{
Nadir Yehya ${ }^{1}$ Neal J. Thomas ${ }^{2}$ \\ 1 Department of Anesthesiology and Critical Care Medicine, \\ Children's Hospital of Philadelphia and University of Pennsylvania, \\ Philadelphia, Pennsylvania, United States \\ 2 Division of Pediatric Critical Care Medicine, Department of Pediatrics \\ and Public Health Science, Penn State Hershey Children's Hospital, \\ Hershey, Pennsylvania, United States \\ J Pediatr Intensive Care 2019;8:32-41.
}

Address for correspondence Nadir Yehya, MD, Department of Anesthesiology and Critical Care Medicine, Children's Hospital of Philadelphia, Suite 7C-26, 34th Street and Civic Center Boulevard, Philadelphia, PA 19104, United States

(e-mail: yehyan@email.chop.edu).
Abstract
Keywords
- sepsis
- septic shock
- children
- pediatric
- acute respiratory distress syndrome
- pediatric acute respiratory distress syndrome

The epidemiology of the acute respiratory distress syndrome (ARDS) in pediatric sepsis is poorly defined. With significant data extrapolated from adult studies in sepsis and ARDS, sometimes with uncertain applicability, better pediatric-specific guidelines and dedicated investigations are warranted. The recent publication of a consensus definition for pediatric ARDS (PARDS) is the first step in addressing this knowledge gap. The aim of this review is to frame our current understanding of PARDS as it relates to pediatric sepsis, encompassing epidemiology, pathophysiology, and management. We argue that addressing the role of PARDS in pediatric sepsis requires significant attention to details with respect to how PARDS and sepsis are defined to accurately describe their epidemiology, natural history, and outcomes. Finally, we highlight certain aspects of PARDS management as they relate to the septic child and offer suggestion for future directions in this field.

\section{Introduction}

Pediatric definitions of syndromes, including acute respiratory distress syndrome (ARDS), are predominantly extrapolated from adult definitions with uncertain applicability. In addition to definitions, pediatric ARDS (PARDS) management has often been extrapolated from adults or premature neonates, similarly without sensitivity to the distinct epidemiology and potentially pathogenesis of pediatrics. With respect to pediatric sepsis, this has led to imprecision with respect to understanding the prevalence, incidence, and implications of PARDS within the cohort of children with sepsis. The goal of this review is to frame PARDS as it applies to children with sepsis, focusing on PARDS caused by pneumonia and by nonpulmonary sepsis. By necessity, given the paucity of data in children, there is substantial reference to the adult literature but pediatric specifics are included whenever possible. Finally, select aspects of PARDS management are discussed with a focus on their applicability in septic children.

received

September 15, 2018 accepted after revision

October 17, 2018

published online

December 10, 2018

\section{Definitions of Acute Respiratory Distress Syndrome in Pediatrics}

The initial description of ARDS by Ashbaugh et $\mathrm{al}^{1}$ in their landmark case series in 1967, detailed, for the first time, the pathophysiological constellation of pulmonary abnormalities common to 12 patients with a diverse array of inciting insults. Their patients exhibited severe dyspnea, cyanosis refractory to oxygen therapy, diffuse alveolar infiltrates on chest radiograph, decreased pulmonary compliance, and hyaline membrane formation on pathology. Four of these 12 listed "viral pneumonia" as a potential etiology which was the only infectious etiology listed. It is also notable that this initial description of ARDS, based on the oxygenation information provided in this report, would have classified as severe ARDS in modern nomenclature.

ARDS, as a concept, underwent development over the next several decades with formalized stratifications coming in 1988 with the Murray's lung injury score ${ }^{2}$ and the more

Copyright (c) 2019 by Georg Thieme Verlag KG, Stuttgart · New York
DOI https://doi.org/ 10.1055/s-0038-1676133. ISSN 2146-4618.
Septic Shock; Guest Editor: E. Scott Halstead, MD, PhD. 
commonly adopted 1994 American-European Consensus Conference (AECC) definition ${ }^{3}$ to assist with providing a common language for epidemiological and interventional studies. The AECC definition provided the framework for defining ARDS as acute onset hypoxemia $\left(\mathrm{PaO}_{2} / \mathrm{FiO}_{2} \leq 200\right)$ with bilateral pulmonary infiltrates in the setting of a pulmonary wedge pressure $<18 \mathrm{~mm} \mathrm{Hg}$. AECC also introduced a broader concept of "acute lung injury" (ALI), with inclusion of milder oxygenation deficiencies $\left(\mathrm{PaO}_{2} / \mathrm{FiO}_{2}\right.$ $\leq 300$ ), and the more specific category of ARDS limited to lower $\mathrm{PaO}_{2} / \mathrm{FiO}_{2}$. In the subsequent 20 years, mostly using the AECC definition, clinical trialists performed multiple interventional trials on adults with ALI and ARDS, predominantly with negative results. ${ }^{4-14}$ Exceptions to this trend were the large trial comparing different tidal volumes and plateau pressures $^{15}$ and conservative versus liberal fluid strategies. ${ }^{16}$ The negative trials highlighted certain concerns with the AECC definition; specifically, a lack of detail and potential inclusion of too broad of a population, several of which did not have the ARDS "syndrome" described by Ashbaugh ${ }^{1}$, but milder hypoxemia without the essential pathophysiology and poor prognosis described in 1967.

A group convened in Berlin in 2012 to reassess and redefine ARDS, ${ }^{17}$ attempting to address some of these limitations of the AECC definition. Acute was clarified to $\leq 7$ days of an inciting insult, computed tomography (CT) was allowed to reinforce or replace the radiograph, and the absence of heart failure as the predominant cause for hypoxemia was allowed to be diagnosed noninvasively, in light of declining use of pulmonary artery catheters in the intensive care unit (ICU). Most importantly, hypoxemia was redefined as mild $\left(\mathrm{PaO}_{2} / \mathrm{FiO}_{2}>200\right.$ and $\left.\leq 300\right)$, moderate $\left(\mathrm{PaO}_{2} / \mathrm{FiO}_{2}>\right.$ 100 and $\leq 200)$, and severe $\left(\mathrm{PaO}_{2} / \mathrm{FiO}_{2} \leq 100\right)$, with a minimum end-expiratory pressure (invasive or noninvasive) of $5 \mathrm{~cm} \mathrm{H} \mathrm{H}_{2} \mathrm{O}$ for mild ARDS, and invasive for moderate and severe. The confusing AECC "ALI non-ARDS" category $\left(\mathrm{PaO}_{2} /\right.$ $\mathrm{FiO}_{2}>200$ and $\leq 300$ ) was eliminated. The authors of the Berlin definition demonstrated marginal improvement in the prediction of mortality and duration of ventilation relative to AECC. Interestingly, concurrent with the publication of these revised definitions was the publication of two positive trials in adult ARDS which implicitly validated their utility and highlighted the shortcomings of AECC. The ACURASYS (ARDS et Curarisation Systematique) trial, ${ }^{18}$ which tested the utility of early cisatrcurium, limited enrollment to patients with $\mathrm{PaO}_{2} / \mathrm{FiO}_{2} \leq 150$, rather than the typical $\leq 300$. PROSEVA (Prone Position in Severe ARDS) had even more stringent enrollment criteria, ${ }^{19}$ requiring $\mathrm{PaO}_{2} / \mathrm{FiO}_{2} \leq 150$ after 12 to 24 hours of stabilization, thus excluding patients who rapidly improved with standard ventilator management. In both cases, the goal was enrichment of a higher risk population in which the tested intervention could plausibly impact mortality with a reasonable sample size. This avoided unnecessarily randomizing lowrisk patients with a high likelihood of survival irrespective of treatment arm, thereby diluting any treatment effect.

In neither the AECC nor Berlin definitions of ARDS were pediatric considerations addressed. Absent such, AECC and
Berlin definitions have been applied to pediatrics without modification, despite the distinct epidemiology and outcomes of children with ARDS. ${ }^{20-23}$ For instance, children have a different comorbidity profile than adults. Prematurity occurs in up to $13 \%$ of children with PARDS $^{24}$ and children have distinct risk factors for right ventricular dysfunction and pulmonary hypertension relative to adults. ${ }^{25}$ Arterial blood gases are less commonly used in children, precluding the use of $\mathrm{PaO}_{2}$ in defining severity of lung injury. ${ }^{26-29}$ Finally, PARDS has approximately half the mortality of adult ARDS, 24,30-32 affecting the choice of outcomes for clinical trials.

To address these limitations, the Pediatric Acute Lung Injury and Sepsis Investigators sponsored the Pediatric Acute Lung Injury Consensus Conference (PALICC) ${ }^{33}$ to propose definitions for PARDS. Notable differences in the 2015 PALICC definition ${ }^{34}$ are use of oxygenation index (OI) instead of $\mathrm{PaO}_{2} /$ $\mathrm{FiO}_{2}$, alternative stratification based on $\mathrm{SpO}_{2}$ rather than $\mathrm{PaO}_{2}$ (oxygen saturation index, OSI), ${ }^{26,27}$ and less restrictive radiographic criteria (unilateral infiltrates). Concessions are made for defining PARDS while on noninvasive support for children undergoing chronic mechanical ventilation at baseline, and for children with unrepaired cyanotic congenital heart disease. This represented the first attempt to develop a classification system specific to pediatrics, a necessary and welcome step for the field. The adoption of a parallel $\mathrm{Spo}_{2}-$ based classification system is necessary, given the variable utilization of arterial catheters. However, this initial iteration also carries some inherent risks similar to those of the adult AECC definition. Specifically, timing of oxygenation is not specified, despite the known differential utility of $\mathrm{PaO}_{2} / \mathrm{FiO}_{2}$ (or OI) depending on when the measurement is made. ${ }^{20,23,35}$ Finally, the more liberal radiographic criteria (unilateral versus bilateral infiltrates) risks inclusion of unilateral pneumonias and bronchiolitis which are poorly differentiated using chest radiograph alone. This could potentially lead to the same drawbacks as the AECC definition with respect to lack of specificity, inclusion of too broad a population with a lower overall mortality risk, and description of a broader syndrome which is further away from the one initially described in 1967. In other words, it remains to be seen whether PARDS is "real" ARDS, and more importantly, whether this distinction even matters. Future prospective studies using modern definitions of PARDS will need to be rigorously evaluated and updated for the construct definition of this syndrome to be considered useful for either clinical care or for research.

\section{Epidemiology and Natural History}

\section{Prevalence of PARDS in Pediatric Sepsis}

The prevalence of PARDS among pediatric sepsis cases is unknown. As can be surmised by the previous section, prevalence will depend upon the definition of PARDS used, with a higher rate reported with more permissive definitions (noninvasive $\mathrm{Spo}_{2}$-based criteria, unilateral infiltrates on chest radiograph). Complicating matters even further is the likelihood that PARDS prevalence will likely vary depending on the definition of sepsis used. ${ }^{36,37}$ 
However, despite the lack of a dedicated epidemiological study, some evidence exists related to how common PARDS is in pediatric sepsis. RESOLVE (REsearching severe Sepsis and Organ dysfunction in children: a gLobal perspectiVE) was the largest randomized, placebo-controlled trial conducted in pediatric septic shock to date. ${ }^{38}$ The study compared drotrecogin alfa (activated) against placebo in children with severe sepsis, enrolling 477 children representing 18 countries between 2002 and 2005. Enrollment was restricted to children with sepsis-induced cardiovascular and respiratory dysfunction as defined by the International Pediatric Sepsis Consensus Conference, ${ }^{39}$ attempting to enrich for a sicker, critically ill population. Overall mortality was $17 \%$ in the trial. Using the strict inclusion criteria (including some requirement for respiratory dysfunction), only 42 children (9\%) met criteria for ARDS (likely using AECC definitions, although undefined in the study). This low rate might reflect some of the limitations of the AECC definition, such as the requirement for an arterial blood gas which may preclude diagnosing PARDS, thus underestimating prevalence.

On the other extreme, SPROUT (Sepsis PRevalence, OUtcomes, and Therapies), the recent international pediatric sepsis point-prevalence study reported that $83 \%$ of children had respiratory organ dysfunction at presentation, suggesting a much higher prevalence of PARDS. ${ }^{40}$ SPROUT used the 2005 International Pediatric Sepsis Consensus Conference definitions for organ failure ${ }^{39}$ which described respiratory failure as (1) $\mathrm{PaO}_{2} / \mathrm{FiO}_{2}<300$, (2) $\mathrm{PaCO}_{2}>65$ torr (or 20 above baseline), (3) $\mathrm{Fio}_{2}>0.5$ to keep $\mathrm{spo}_{2}>92 \%$, or (4) nonelective invasive or noninvasive ventilation. Clearly the more liberal 2005 definition of "respiratory failure" used here is not synonymous with PARDS, likely due to the inclusion of nonelective ventilation, and would lead to an overestimation of PARDS in pediatric sepsis if applied without modification. The true prevalence of PARDS in pediatric sepsis likely exists between these two extremes: higher than the $9 \%$ using strict AECC definitions in the setting of a clinical trial, and lower than the $83 \%$ using a loose definition of "respiratory dysfunction." This question could be addressed by using modern definitions of ARDS, such as the Berlin definition, making allowances for noninvasive $\left(\mathrm{Spo}_{2}\right.$ versus $\left.\mathrm{PaO}_{2}\right)$ when necessary. ${ }^{29}$ Alternatively, the 2015 PALICC definition of PARDS which explicitly has parallel $\mathrm{Spo}_{2}-$ based stratification could be utilized. ${ }^{34}$ Irrespective of definition, the actual prevalence of PARDS in sepsis along with any associated morbidity or mortality risk carried alongside the diagnosis is unknown and requires dedicated epidemiological study using clear and accepted definitions.

\section{Sepsis Resulting in PARDS and Associated Outcomes}

While the prevalence of PARDS in sepsis is poorly defined, the prevalence of infection as the inciting etiology for PARDS has received greater study. Infectious pneumonias causing "direct" lung injury are typically the most common cause of PARDS, with estimates ranging from $35^{21,22}$ to $58 \% 35$ of cases. Nonpulmonary sepsis causing an "indirect" lung injury is typically the second most common PARDS etiology, responsible for $13^{21}$ to $32 \%{ }^{22}$ The distinction between pulmonary and nonpulmonary infection is relevant for understanding and linking the epidemiology of PARDS and sepsis, especially since an isolated infectious pneumonia, even one severe enough to meet PARDS criteria may not satisfy criteria for pediatric sepsis. ${ }^{39}$ The distinction gains greater prognostic relevance when considering that adult sepsis outcomes are highly dependent upon site of infection. ${ }^{41}$ It is unknown whether pediatric sepsis exhibits a similar relationship between site of infection and outcome and whether presence of PARDS impacts this relationship. Notably, in several PARDS cohorts, nonpulmonary sepsis possesses higher mortality than infectious pneumonia. ${ }^{21-23}$ However, it is unclear whether the higher mortality seen in nonpulmonary sepsis associated PARDS is intrinsic to the site of infection or whether nonpulmonary sepsis is simply related to increasing number of organ failures.

Mortality in PARDS is generally lower than for adult ARDS and is decreasing over time. ${ }^{35,42}$ In recent cohorts, mortality approaches levels as low as $11 \% .^{35,43,44}$ In PARDS, increasing number of nonpulmonary organ failures is associated with a linear increase in mortality risk ${ }^{21-23,35}$ which may explain the higher mortality reported for PARDS from nonpulmonary sepsis relative to PARDS from infectious pneumonia, as a disseminated infection would be expected to affect more distal organs than a localized one. Other consistent predictors of mortality include immunocompromised status ${ }^{21,22,35,43}$ and severity of hypoxemia. ${ }^{20-23,29,35,45}$ Elevated ventilator pressures have also been associated with increased mortality, ${ }^{22,46}$ although it is not clear whether this reflects increased severity of pulmonary disease or injurious ventilation causing subsequent ventilator-induced lung injury. Fluid balance has been associated with longer duration of ventilation ${ }^{44,47,48}$ and with mortality, ${ }^{48}$ although it is similarly unclear if this is causal or a marker of severity of illness. Notably, classic risk factors for mortality in PARDS, such as immunocompromised status and oxygenation are only relevant to PARDS caused by an infection. ${ }^{24}$ This suggests that future studies of PARDS should be stratified, as in adults, by the presence or absence of sepsis as this subtype appears to possess a distinct phenotype.

\section{Pathogenesis of Pediatric Acute Respiratory Distress Syndrome in Sepsis}

PARDS results from altered alveolar permeability after an inciting insult, with alterations in both endothelial and alveolar epithelial barrier properties. Several lines of evidence suggest that neutrophils mediate much of this damage. A full review of the inflammatory changes leading to alveolar flooding are beyond the scope of this review; however, certain aspects specific to sepsis are worth discussing in greater detail.

\section{Role of the Lung}

In sepsis of a pulmonary origin, direct epithelial injury can result from the underlying infection, ${ }^{49,50}$ disseminating and propagating to involve multiple areas of the lung in severe cases, thus meeting criteria for adult ARDS and PARDS. ${ }^{50}$ Interestingly, in addition to direct pulmonary damage, invasive mechanical ventilation may propagate a localized pneumonia into a systemic condition. In a mouse model of pneumonia, 
mechanical ventilation led to subsequent worsening of pulmonary edema and inflammation, as well as increased systemic inflammatory cytokine levels ${ }^{51}$ suggesting that mechanical ventilation, particularly if injurious, can aggravate and spread a localized lung injury.

Additionally, animal experimental abdominal sepsis demonstrated neutrophil extracellular trap (NET) formation in the lung following cecal ligation and puncture. NETs are webs composed of extracellular DNA and associated histones as a result of chromatin degradation, as well as some associated cytoplasmic proteins. NETs are released from dying neutrophils in response to infectious and inflammatory stimuli, ${ }^{52}$ a form of cell death referred to as NETosis ${ }^{53}$ and tend to form in pulmonary capillaries. ${ }^{54-56}$ NET formation can also be stimulated and propagated by activated platelets during inflammation. ${ }^{54}$ NETs have antimicrobial properties, predominantly by trapping and killing circulating microbes and inactivating virulence factors. ${ }^{55,57}$ The interaction of NETs with platelets can also trigger thrombosis, ${ }^{56,58}$ thereby linking the coagulation system and innate immunity during infection. Microthrombi foster compartmentalization of bacteria during infection and prevent bacterial invasion into tissue ${ }^{58}$; however, microthrombi formation in the pulmonary vasculature can also lead to some of the pathophysiological derangements seen in sepsis-associated lung injury. Additionally, NET components, specifically histones, ${ }^{59}$ are toxic to multiple cell types, including endothelial and alveolar epithelial cells, ${ }^{60-63}$ potentially providing another link between nonpulmonary sepsis and subsequent lung injury.

\section{Role of Circulating Damage Associated Molecular Patterns}

As described above, histones in sepsis are functioning as damage-associated molecular patterns (DAMPs), endogenous molecules released in response to stress, trauma, or infection which are recognized by the same pattern recognition receptors designed to target exogenous infections. Pattern recognition receptors, including the toll-like receptors (TLRs) and the NOD-like receptors (NLRs), are primitive components of innate immunity designed to recognize pathogen-associated molecular patterns (PAMPs) from microbes (such as lipopolysaccharide) and endogenous DAMPs (reviewed in ${ }^{64}$ ). Unlike PAMPs, DAMPs are host-derived and can perpetuate the inflammatory response initiated by infection or themselves initiate a similar noninfectious inflammatory response. Chromatin-associated histones ${ }^{59}$ and high-mobility group box 1 (HMGB1) ${ }^{65}$ function as DAMPs. Mitochondrial DNA has been demonstrated to function as a DAMP and worsen lung injury $^{66,67}$ and is correlated with nonsurvival in critically ill humans. ${ }^{68-70}$

\section{Management of Pediatric Acute Respiratory Distress Syndrome}

\section{Managing PARDS in the Critically III Septic Child}

The goals of PARDS management in septic children are coincident with the goals of sepsis management: recogni- tion, timely antibiotics and source control, adequate initial resuscitation using fluids and vasopressors, decreasing wasteful oxygen consumption and deresuscitating once physiology is controlled. For subjects in which their sepsis is complicated by PARDS, assisted breathing using noninvasive or invasive ventilation contributes to decreasing oxygen consumption and redirecting cardiac output away from respiratory muscles toward other vital organs. Management of PARDS from sepsis is based on excellent supportive care, as no targeted therapies exist. Specific aspects of this supportive care are discussed below.

\section{Fluid Resuscitation}

There is concern regarding excessive fluid resuscitation in sepsis with concurrent PARDS or a fear of causing PARDS due to resuscitation itself. The fluid expansion as supportive therapy (FEAST) trial in febrile African children with poor perfusion demonstrated higher mortality with both albumin and saline boluses, relative to no bolus. ${ }^{71}$ Although this trial has poor external generalizability to sepsis and PARDS management in developed and resource-rich settings, it does highlight potential risks associated with fluid resuscitation. A large body of observational literature also supports risks associated with fluid overload, ${ }^{44,47}$ although such studies cannot assign causality to fluid overload and excessive fluid administration coupled with inadequate diuresis may simply be markers of severity of illness. The exact endpoints of fluid resuscitation in sepsis are unknown, with or without PARDS. When to switch resuscitative efforts away from fluids and toward vasoactives is similarly unknown. These remain areas of active investigation in adult sepsis, with the ongoing crystalloid liberal or vasopressors early resuscitation in sepsis (CLOVERS) trial. In the meantime, it is reasonable to consider the pulmonary status during sepsis resuscitation and to curtail fluid administration earlier if a subject has PARDS or appears to be developing PARDS. In environments with noninvasive and invasive mechanical ventilations readily available, patients should have respiratory failure quickly recognized and appropriate support aggressively initiated.

\section{Noninvasive Support}

Increasing attention has been devoted to noninvasive support for PARDS. Most studies have investigated noninvasive positive pressure ventilation (PPV) ${ }^{72-77}$ in the form of continuous positive airway pressure (CPAP) or bi-level positive airway pressure (BiPAP), although increasing attention is being devoted to humidified high flow nasal cannula (HFNC). In observational studies of pediatric acute respiratory failure treated with noninvasive PPV, predictors of noninvasive success (typically defined as avoiding endotracheal intubation) included improvement in hypoxemia, ${ }^{74,75}$ better initial $\mathrm{pH},{ }^{77}$ lower severity of illness with fewer organ failures, ${ }^{73,74}$ and improved respiratory rate. ${ }^{74}$ These findings were confirmed in the only randomized trial to date of noninvasive PPV in children. ${ }^{78}$ In this study of 50 children, early use of noninvasive PPV improved oxygenation, heart rate, and respiratory rate within 6 hours of initiation and reduced the rate of intubation from 60 to $28 \%$. 
There is specific interest in noninvasive support for immunocompromised children. In a study limited to immunocompromised children with respiratory failure, noninvasive success was also associated with improved heart rates and respiratory rates. ${ }^{72} \mathrm{~A}$ separate study of 239 immunocompromised children, of whom 120 initially received noninvasive PPV, confirmed that cardiovascular dysfunction was an independent predictor of failure of noninvasive PPV. ${ }^{76}$ However, noninvasive PPV was successful in $74 \%$ of cases, as only 31 of the 120 managed initially with noninvasive PPV required intubation.

Operationally, this suggests that potentially good candidates with PARDS for noninvasive PPV support are those with isolated respiratory failure with a quantifiable improvement in hypoxemia and respiratory effort within 6 hours of initiation, including immunocompromised children with isolated respiratory failure. Patients with vasopressor-dependent septic shock, additional nonpulmonary organ dysfunctions, or a poor physiologic response to a trial of noninvasive support appear likely to be better served with invasive ventilation. Given the recently completed trial ${ }^{79}$ demonstrating superiority of helmet versus facemask interface in adults with ARDS (18 vs. $61.5 \%$ subsequent intubation), the optimal pediatric non-|invasive PPV interface remains an open question.

Humidified HFNC has been studied predominantly in bronchiolitis in children, ${ }^{80}$ with no studies specific to children with PARDS. Understandably, there is reluctance to initiate a more novel first-line therapy in more severe respiratory failures, such as PARDS. However, HFNC does retain some promise and further research into the utility of HFNC for PARDS was recommended by PALICC. ${ }^{81}$ In a single observational study of HFNC in adults with ARDS, ${ }^{82}$ with an intubation rate of $40 \%$, additional organ failures, hemodynamic instability, worse oxygenation, and higher respiratory rate after initiation were all associated with failure of HFNC. The authors conclude that HFNC can be used as first-line therapy even for severe respiratory failure, including ARDS. It is notable that over $80 \%$ of HFNC cases in this study were pneumonia, weighting this cohort toward direct pulmonary etiologies of ARDS. It remains unclear how well HFNC would perform in a disseminated, nonpulmonary septic cohort, particularly with ongoing hemodynamic instability, and septic shock. Given the association between increasing organ failures and poor physiologic response after HFNC initiation, similar cautions appear warranted for HFNC in PARDS as apply for noninvasive PPV. Future studies should focus on the utility of these noninvasive modes for initial support, likely restricted to mild and moderate PARDS, as recommended by PALICC. $^{81}$

\section{Invasive Mechanical Ventilation}

The optimal ventilator strategy, settings, and adjunct treatments are unknown in PARDS. Three therapies have been tested in PARDS: high frequency oscillatory ventilation (HFOV), ${ }^{83}$ prone positioning, ${ }^{84}$ and exogenous surfactant, ${ }^{85,86}$ none of which demonstrated significant advantages over standard care. For this reason, most PARDS management is based on expert (and local) consensus ${ }^{34}$ and several therapies of uncertain utility (inhaled nitric oxide or prostacyclin, prone positioning, surfactant, neuromuscular blockade, corticosteroids) remain utilized only for refractory cases of severe PARDS. Extrapolation from adult studies must proceed with extreme caution, since the epidemiology and outcomes of PARDS are distinct from adults, even when using similar definitions. ${ }^{29,35,45}$

The guiding principle of adult ARDS management is lungprotective ventilation, as manifest by limited tidal volumes $\left(\mathrm{V}_{\mathrm{T}}\right)$ and distending pressures. ${ }^{15,87}$ It is unclear whether this applies to children, as there has been no association between increasing $\mathrm{V}_{\mathrm{T}}$ and poor outcomes in PARDS. ${ }^{46,88}$ Elevated peak pressures have been associated with poor outcomes in PARDS $^{22,46}$ but it is unclear whether this is causal or simply reflects more severe lung injury. While $\mathrm{V}_{\mathrm{T}} \leq 6 \mathrm{~mL} / \mathrm{kg}$ have been recommended for pediatric ARDS, ${ }^{89}$ the ambiguity regarding the utility of low $\mathrm{V}_{\mathrm{T}}$ in children has led to average $\mathrm{V}_{\mathrm{T}}$ closer to $8 \mathrm{~mL} / \mathrm{kg}$ in published pediatric ARDS cohorts, ${ }^{22,90}$ and substantial utilization of $\mathrm{V}_{\mathrm{T}}>10 \mathrm{~mL} / \mathrm{kg} .{ }^{90}$

Prone positioning ${ }^{19}$ and early short-term neuromuscular blockade ${ }^{18}$ have also demonstrated improved survival in moderate/severe ARDS in adults (PROSEVA and ACURASYS, discussed earlier). The pediatric prone positioning trial was stopped early for futility, ${ }^{84}$ with an overall $8 \%$ mortality rate. However, prone positioning remains a rescue therapy for severe PARDS, ${ }^{35}$ raising the question of whether a trial restricted to severe PARDS (as in adults) would provide a more definitive answer for pediatrics. Neuromuscular blockade has never been systematically assessed in PARDS and its utility remains unknown. It is commonly used in PARDS as an adjunct for improving ventilator synchrony and improving oxygenation. ${ }^{35}$ In PARDS caused by sepsis, paralysis can also contribute to further reduction of oxygen consumption. Because of a concern for contributing to myopathy and weakness after critical illness, neuromuscular blockade should be discontinued as soon as feasible; in ACURASYS, adult subjects were exposed to cisatracurium for only 48 hours with no increase in subsequent paresis or myopathy. ${ }^{18}$

Two large trials of HFOV in adult ARDS demonstrated either no benefit ${ }^{91}$ or worse outcomes with HFOV. ${ }^{92}$ The sole pediatric trial is limited in interpretation due to significant crossover $^{83}$ and was negative for significant clinical endpoints. Extrapolation of the adult HFOV data to children is problematic due to the protocols and manner in which HFOV was used and HFOV remains a commonly utilized rescue therapy for PARDS. ${ }^{93}$ HFOV is likely better tolerated in children, relative to adults, given the lower prevalence of cardiac dysfunction. It may be particularly useful in PARDS from sepsis when severe pulmonary and extra-pulmonary edema (chest wall edema, ascites) are contributing to progressive atelectasis requiring a high sustained mean airway pressure for sustained recruitment.

\section{Extracorporeal Support}

Extracorporeal membrane oxygenation (ECMO) is increasingly being utilized for refractory PARDS and for pediatric septic shock. Modern circuitry and oxygenators, as well as increasing familiarity with ECMO at specialized higher 
volume centers, have led to increased willingness to use ECMO on increasingly complex patients without an appreciable increase in mortality rates. ${ }^{94}$ In an analysis of the Extracorporeal Life Support Organization's (ELSO) database of pediatric respiratory failure between 1993 and 2007, mortality was relatively unchanged over 15 years for all comers, approximating $43 \% .{ }^{94}$ However, the number of patients with comorbid conditions more than doubled, suggesting an increased aggressiveness in ECMO utilization in populations previously deemed futile. Notably, PARDS associated with (presumably nonpulmonary) sepsis had worse mortality (60\%, relative to $30-44 \%$ for bacterial and viral pneumonias) and was an independent predictor of nonsurvival in multivariate analysis. Consistent predictors of mortality for pediatric ECMO were length of pre-ECMO mechanical ventilation, ${ }^{94,95}$ especially above 14 days, ${ }^{94}$ severity of PARDS prior to ECMO cannulation, ${ }^{94,95}$ organ failures and immunocompromised status, ${ }^{94,96,97}$ and ECMO duration of greater than 21 days. ${ }^{95,98}$ Stem cell transplant carries a particularly poor prognosis with reported mortality rates over $95 \%{ }^{96,97}$

Interestingly, in light of the poor prognosis associated with PARDS from sepsis in ELSO, the Royal Children's Hospital in Melbourne, Australia, reported their single center experience and a mortality rate of only $26 \%$ in children with refractory septic shock. ${ }^{99}$ In 23 children with refractory septic shock, 22 (96\%) of whom had 3 or more organ failures, institutional practice was initiation of ECMO via cannulation of the right atrium and aorta (central ECMO) after sternotomy. The authors concluded that central ECMO was associated with improved outcomes predominantly by achieving higher flow rates, up to 10 L per minute, and thus more effectively reversing shock and mitigating worsening multisystem organ failure. Also, having the return cannula in the ascending aorta, rather than the right carotid, may be associated with improved coronary and cerebral perfusion. Concerns regarding routine central cannulation include a risk of bleeding and mediastinitis, as well as the possibility of being able to achieve higher flow rates with two peripheral venous cannulas. Additionally, as centers gain experience with ECMO, the threshold at which ECMO is offered as a salvage therapy is lowered, thus making comparisons with historical groups difficult, as analyses now include the survival of children who (historically) may have survived without ECMO.

The recent ECMO to Rescue Lung Injury in Severe ARDS (EOLIA) trial shed some light on the efficacy of ECMO for adult severe ARDS. ${ }^{100}$ In this trial of 249 subjects, of whom 158 (63\%) had pneumonia, ECMO resulted in $24 \%$ lower mortality ( $p=0.09$ ) relative to continued mechanical ventilation. Of note, $28 \%$ of subjects assigned to receive mechanical ventilation were rescued with ECMO, and analysis of the secondary outcome of "treatment failure" was highly significant in favor of ECMO $(p<0.001)$. While not strictly a positive trial, EOLIA contributes to our knowledge that ECMO is a viable strategy in adult severe ARDS and reinforces that it should be considered relatively early in the ARDS course.

Absent a trial, efficacy and timing concerns remain difficult to address in pediatrics. For now, ECMO seems reasonable to offer as a salvage therapy in patients with refractory septic shock and associated cardiovascular or respiratory failure in centers experienced in ECMO. Patient selection remains key as certain comorbidities, such as stem cell transplant portend a substantially higher likelihood of mortality. Center experience may also play a role as a retrospective examination of the Pediatric Health Information System database suggests that a minimum annual case load of 22 ECMO runs/center/year was associated with improved mortality, ${ }^{101}$ a finding which requires further validation. Finally, given the worse prognosis associated with prolonged ECMO runs, discussions with caregivers and family regarding realistic expectations are necessary when patients fail to improve after several weeks of ECMO therapy. However, an exact cut-off for what constitutes "too long" is unknown.

\section{Corticosteroids}

Enthusiasm for hydrocortisone in septic shock was reignited after Annane et al $^{102}$ randomized adults with vasopressorrefractory septic shock within 8 hours to hydrocortisone + fludrocortisone versus placebo, demonstrating that steroid replacement hastened shock reversal and improved mortality, particularly in patients with inadequate cortisol response $(\leq 9 \mu \mathrm{g} / \mathrm{dL})$ to $250 \mu \mathrm{g}$ adrenocorticotropic hormone (ACTH). The subsequent negative Corticosteroid Therapy of Septic Shock (CORTICUS) trial $^{103}$ which allowed enrollment of patients in whom shock had resolved up to 72 hours, tempered enthusiasm by failing to reproduce the results of Annane et al, and cast further uncertainty about the utility of ACTH stimulation. The lower mortality in CORTICUS highlights the importance of patient selection and illness severity in determining which population, if any, may benefit from hydrocortisone replacement.

Every observational study of pediatric sepsis ${ }^{40,104-108}$ has failed to demonstrate a benefit of corticosteroid use. A single study of PARDS investigating the association between all corticosteroids (methylprednisolone as well as hydrocortisone) similarly demonstrated worse outcomes with corticosteroid exposure. ${ }^{109}$ All of these studies are hampered by confounding indication with corticosteroid use typically restricted to more severely ill patients, a dilemma which can only be resolved by a clinical trial. The sole trial of corticosteroids for PARDS was limited to 35 total patients, and demonstrated marginal improvements in oxygenation and ventilation with methylprednisolone use but no difference in outcomes. ${ }^{110}$ However, this trial did demonstrate feasibility, and the question of corticosteroids in sepsis and PARDS must be addressed. The question of hydrocortisone in pediatric sepsis likely should be addressed first, as sepsis is more prevalent than PARDS. The question of which patients should be randomized, the utility of ACTH stimulation versus cortisol levels, ${ }^{111}$ the dosing of hydrocortisone, ${ }^{112}$ and the utility of additional fludrocortisone all need to be addressed in the design of such a trial.

A secondary clinical question arises regarding the role of corticosteroids in PARDS. The trial of Drago et $\mathrm{al}^{110}$ enrolled patients at PARDS onset but adult trials of ARDS have typically studied methylprednisolone in refractory (for $>7$ days) ARDS. ${ }^{6,113}$ A pediatric trial will need to determine which population should be randomized (all PARDS, early vs. late, 
mild vs. severe), which dose of methylprednisolone to use, and how to account for contamination by hydrocortisone use for shock. Exclusion of hydrocortisone exposed children would likely render the trial impractical, as it will enrich for a less sick population, which is arguably the ones least likely to benefit from corticosteroids.

Appropriate recommendations regarding which patients would benefit from hydrocortisone for shock (or methylprednisolone for PARDS) is critical to ensure that the benefits of treatment are not outweighed by the risks of corticosteroids, including immunosuppression, hospital acquired infections, hyperglycemia, neuromyopathy, and functional impairment. At present, it is difficult to make meaningful recommendations given the paucity of data.

\section{Future Directions}

The field of PARDS in pediatric sepsis is in its infancy. With new pediatric-specific definitions for PARDS, a detailed examination of the clinical epidemiology and natural history of PARDS in sepsis is needed. Two necessary and important questions to address are: (1) what is the prevalence of PARDS in pediatric sepsis and (2) is PARDS causal for mortality in pediatric sepsis. Basic and translational studies are needed to better understand the pathogenesis of lung injury in sepsis and whether this pathogenesis differs by patient age or by location and type of inciting infection. Finally, after a better understanding of the underlying physiology, clinical trials are sorely needed for both pediatric sepsis and PARDS to address the best way to support these sick children. The optimal type of mechanical ventilation, the role of refractory therapies including corticosteroids, HFOV, and ECMO, and the adequacy of nutrition and fluid management all remain unclear and are currently driven by regional culture. The development of multicenter registries and collaborations will be needed to break out of our current model of single center observational studies. We have generated multiple hypotheses over the past 30 years; it is time to test them.

\section{Conflict of Interest}

Dr. N.J.T. reports grants from Gene Fluidics, Therabon, and CareFusion during the conduct of the study.

Dr. N.Y. reports grants from NHLBI during the conduct of the study.

\section{References}

1 Ashbaugh DG, Bigelow DB, Petty TL, Levine BE. Acute respiratory distress in adults. Lancet 1967;2(7511):319-323

2 Murray JF, Matthay MA, Luce JM, Flick MR. An expanded definition of the adult respiratory distress syndrome. Am Rev Respir Dis 1988;138(03):720-723

3 Bernard GR, Artigas A, Brigham KL, et al. The American-European Consensus Conference on ARDS. Definitions, mechanisms, relevant outcomes, and clinical trial coordination. Am J Respir Crit Care Med 1994;149(3, Pt 1):818-824

4 Taylor RW, Zimmerman JL, Dellinger RP, et al; Inhaled Nitric Oxide in ARDS Study Group. Low-dose inhaled nitric oxide in patients with acute lung injury: a randomized controlled trial. JAMA 2004;291(13):1603-1609

5 Zeiher BG, Artigas A, Vincent JL, et al; STRIVE Study Group. Neutrophil elastase inhibition in acute lung injury: results of the STRIVE study. Crit Care Med 2004;32(08):1695-1702

6 Steinberg KP, Hudson LD, Goodman RB, et al; National Heart, Lung, and Blood Institute Acute Respiratory Distress Syndrome (ARDS) Clinical Trials Network. Efficacy and safety of corticosteroids for persistent acute respiratory distress syndrome. $\mathrm{N} \mathrm{Engl}$ J Med 2006;354(16):1671-1684

7 Matthay MA, Brower RG, Carson S, et al; National Heart, Lung, and Blood Institute Acute Respiratory Distress Syndrome Clinical Trials Network. Randomized, placebo-controlled clinical trial of an aerosolized $\beta_{2}$-agonist for treatment of acute lung injury. Am J Respir Crit Care Med 2011;184(05):561-568

8 Gao Smith F, Perkins GD, Gates S, et al; BALTI-2 study investigators. Effect of intravenous $\beta-2$ agonist treatment on clinical outcomes in acute respiratory distress syndrome (BALTI-2): a multicentre, randomised controlled trial. Lancet 2012;379 (9812):229-235

9 McAuley DF, Laffey JG, O'Kane CM, et al; HARP-2 Investigators; Irish Critical Care Trials Group. Simvastatin in the acute respiratory distress syndrome. N Engl J Med 2014;371(18):1695-1703

10 Truwit JD, Bernard GR, Steingrub J, et al; National Heart, Lung, and Blood Institute ARDS Clinical Trial Network. Rosuvastatin for sepsis-associated acute respiratory distress syndrome. N Engl J Med 2014;370(23):2191-2200

11 Willson DF, Truwit JD, Conaway MR, Traul CS, Egan EE. The Adult Calfactant in Acute Respiratory Distress Syndrome Trial. Chest 2015;148(02):356-364

12 The ARDS Network. Ketoconazole for early treatment of acute lung injury and acute respiratory distress syndrome: a randomized controlled trial. JAMA 2000;283(15):1995-2002

13 Anzueto A, Baughman RP, Guntupalli KK, et al; Exosurf Acute Respiratory Distress Syndrome Sepsis Study Group. Aerosolized surfactant in adults with sepsis-induced acute respiratory distress syndrome. N Engl J Med 1996;334(22):1417-1421

14 Spragg RG, Lewis JF, Walmrath HD, et al. Effect of recombinant surfactant protein C-based surfactant on the acute respiratory distress syndrome. N Engl J Med 2004;351(09):884-892

15 Brower RG, Matthay MA, Morris A, Schoenfeld D, Thompson BT, Wheeler A; Acute Respiratory Distress Syndrome Network. Ventilation with lower tidal volumes as compared with traditional tidal volumes for acute lung injury and the acute respiratory distress syndrome. N Engl J Med 2000;342(18): 1301-1308

16 Wiedemann HP, Wheeler AP, Bernard GR, et al; National Heart Lung, and Blood Institute Acute Respiratory Distress Syndrome (ARDS) Clinical Trials Network. Comparison of two fluid-management strategies in acute lung injury. N Engl J Med 2006;354 (24):2564-2575

17 Ranieri VM, Rubenfeld GD, Thompson BT, et al; ARDS Definition Task Force. Acute respiratory distress syndrome: the Berlin Definition. JAMA 2012;307(23):2526-2533

18 Papazian L, Forel JM, Gacouin A, et al; ACURASYS Study Investigators. Neuromuscular blockers in early acute respiratory distress syndrome. N Engl J Med 2010;363(12):1107-1116

19 Guérin C, Reignier J, Richard JC, et al; PROSEVA Study Group. Prone positioning in severe acute respiratory distress syndrome. N Engl J Med 2013;368(23):2159-2168

20 Trachsel D, McCrindle BW, Nakagawa S, Bohn D. Oxygenation index predicts outcome in children with acute hypoxemic respiratory failure. Am J Respir Crit Care Med 2005;172(02): 206-211

21 Flori HR, Glidden DV, Rutherford GW, Matthay MA. Pediatric acute lung injury: prospective evaluation of risk factors associated with mortality. Am J Respir Crit Care Med 2005;171(09): 995-1001 
22 Erickson S, Schibler A, Numa A, et al; Paediatric Study Group; Australian and New Zealand Intensive Care Society. Acute lung injury in pediatric intensive care in Australia and New Zealand: a prospective, multicenter, observational study. Pediatr Crit Care Med 2007;8(04):317-323

23 López-Fernández Y, Azagra AM, de la Oliva P, et al; Pediatric Acute Lung Injury Epidemiology and Natural History (PEDALIEN) Network. Pediatric Acute Lung Injury Epidemiology and Natural History study: Incidence and outcome of the acute respiratory distress syndrome in children. Crit Care Med 2012; 40(12):3238-3245

24 Yehya N, Keim G, Thomas NJ. Subtypes of pediatric acute respiratory distress syndrome have different predictors of mortality. Intensive Care Med 2018;44(08):1230-1239

25 Himebauch AS, Yehya N, Wang Y, et al. Early Right Ventricular Systolic Dysfunction and Pulmonary Hypertension Are Associated With Worse Outcomes in Pediatric Acute Respiratory Distress Syndrome. Crit Care Med 2018;46(11):e1055-e1062

26 Thomas NJ, Shaffer ML, Willson DF, Shih MC, Curley MA. Defining acute lung disease in children with the oxygenation saturation index. Pediatr Crit Care Med 2010;11(01):12-17

27 Khemani RG, Thomas NJ, Venkatachalam V, et al; Pediatric Acute Lung Injury and Sepsis Network Investigators (PALISI). Comparison of $\mathrm{SpO}_{2}$ to $\mathrm{PaO}_{2}$ based markers of lung disease severity for children with acute lung injury. Crit Care Med 2012;40(04): 1309-1316

28 Wong JJ, Loh TF, Testoni D, Yeo JG, Mok YH, Lee JH. Epidemiology of pediatric acute respiratory distress syndrome in singapore: risk factors and predictive respiratory indices for mortality. Front Pediatr 2014;2:78

29 Khemani RG, Rubin S, Belani S, et al. Pulse oximetry vs. $\mathrm{PaO}_{2}$ metrics in mechanically ventilated children: Berlin definition of ARDS and mortality risk. Intensive Care Med 2015;41(01):94-102

30 Spicer AC, Calfee CS, Zinter MS, et al. A simple and robust bedside model for mortality risk in pediatric patients with acute respiratory distress syndrome. Pediatr Crit Care Med 2016;17(10):907-916

31 Parvathaneni K, Belani S, Leung D, Newth CJ, Khemani RG. Evaluating the performance of the Pediatric Acute Lung Injury Consensus Conference definition of acute respiratory distress syndrome. Pediatr Crit Care Med 2017;18(01):17-25

32 Dowell JC, Parvathaneni K, Thomas NJ, Khemani RG, Yehya N. Epidemiology of cause of death in pediatric acute respiratory distress syndrome. Crit Care Med 2018;46(11):1811-1819

33 Thomas NJ, Jouvet P, Willson D. Acute lung injury in childrenkids really aren't just “little adults". Pediatr Crit Care Med 2013; 14(04):429-432

34 Pediatric Acute Lung Injury Consensus Conference Group. Pediatric acute respiratory distress syndrome: consensus recommendations from the Pediatric Acute Lung Injury Consensus Conference. Pediatr Crit Care Med 2015;16(05):428-439

35 Yehya N, Servaes S, Thomas NJ. Characterizing degree of lung injury in pediatric acute respiratory distress syndrome. Crit Care Med 2015;43(05):937-946

36 Weiss SL, Fitzgerald JC, Maffei FA, et al; SPROUT Study Investigators and Pediatric Acute Lung Injury and Sepsis Investigators Network. Discordant identification of pediatric severe sepsis by research and clinical definitions in the SPROUT international point prevalence study. Crit Care 2015;19:325

37 Balamuth F, Weiss SL, Neuman MI, et al. Pediatric severe sepsis in U.S. children's hospitals. Pediatr Crit Care Med 2014;15(09): 798-805

38 Nadel S, Goldstein B, Williams MD, et al; REsearching severe Sepsis and Organ dysfunction in children: a gLobal perspective (RESOLVE) study group. Drotrecogin alfa (activated) in children with severe sepsis: a multicentre phase III randomised controlled trial. Lancet 2007;369(9564):836-843

39 Goldstein B, Giroir B, Randolph A; International Consensus Conference on Pediatric Sepsis. International pediatric sepsis consensus conference: definitions for sepsis and organ dysfunction in pediatrics. Pediatr Crit Care Med 2005;6(01):2-8

40 Weiss SL, Fitzgerald JC, Pappachan J, et al; Sepsis Prevalence, Outcomes, and Therapies (SPROUT) Study Investigators and Pediatric Acute Lung Injury and Sepsis Investigators (PALISI) Network. Global epidemiology of pediatric severe sepsis: the sepsis prevalence, outcomes, and therapies study. Am J Respir Crit Care Med 2015;191(10):1147-1157

41 Leligdowicz A, Dodek PM, Norena M, Wong H, Kumar A, Kumar A; Co-operative Antimicrobial Therapy of Septic Shock Database Research Group. Association between source of infection and hospital mortality in patients who have septic shock. Am J Respir Crit Care Med 2014;189(10):1204-1213

42 Zimmerman JJ, Akhtar SR, Caldwell E, Rubenfeld GD. Incidence and outcomes of pediatric acute lung injury. Pediatrics 2009;124 (01):87-95

43 Zinter MS, Spicer A, Orwoll BO, et al. Plasma angiopoietin-2 outperforms other markers of endothelial injury in prognosticating pediatric ARDS mortality. Am J Physiol Lung Cell Mol Physiol 2016;310(03):L224-L231

44 Valentine SL, Sapru A, Higgerson RA, et al; Pediatric Acute Lung Injury and Sepsis Investigator's (PALISI) Network; Acute Respiratory Distress Syndrome Clinical Research Network (ARDSNet). Fluid balance in critically ill children with acute lung injury. Crit Care Med 2012;40(10):2883-2889

45 De Luca D, Piastra M, Chidini G, et al; Respiratory Section of the European Society for Pediatric Neonatal Intensive Care (ESPNIC). The use of the Berlin definition for acute respiratory distress syndrome during infancy and early childhood: multicenter evaluation and expert consensus. Intensive Care Med 2013;39 (12):2083-2091

46 Khemani RG, Conti D, Alonzo TA, Bart RD III, Newth CJ. Effect of tidal volume in children with acute hypoxemic respiratory failure. Intensive Care Med 2009;35(08):1428-1437

47 Willson DF, Thomas NJ, Tamburro R, et al; Pediatric Acute Lung and Sepsis Investigators Network. The relationship of fluid administration to outcome in the pediatric calfactant in acute respiratory distress syndrome trial. Pediatr Crit Care Med 2013; 14(07):666-672

48 Flori HR, Church G, Liu KD, Gildengorin G, Matthay MA. Positive fluid balance is associated with higher mortality and prolonged mechanical ventilation in pediatric patients with acute lung injury. Crit Care Res Pract 2011;2011:854142

49 Calfee CS, Janz DR, Bernard GR, et al. Distinct molecular phenotypes of direct vs indirect ARDS in single-center and multicenter studies. Chest 2015;147(06):1539-1548

50 Thille AW, Esteban A, Fernández-Segoviano P, et al. Comparison of the Berlin definition for acute respiratory distress syndrome with autopsy. Am J Respir Crit Care Med 2013;187(07):761-767

51 Müller-Redetzky HC, Will D, Hellwig K, et al. Mechanical ventilation drives pneumococcal pneumonia into lung injury and sepsis in mice: protection by adrenomedullin. Crit Care 2014;18(02):R73

52 Fattahi F, Grailer JJ, Jajou L, Zetoune FS, Andjelkovic AV, Ward PA. Organ distribution of histones after intravenous infusion of FITC histones or after sepsis. Immunol Res 2015;61(03):177-186

53 Fuchs TA, Abed U, Goosmann C, et al. Novel cell death program leads to neutrophil extracellular traps. J Cell Biol 2007;176(02): 231-241

54 Clark SR, Ma AC, Tavener SA, et al. Platelet TLR4 activates neutrophil extracellular traps to ensnare bacteria in septic blood. Nat Med 2007;13(04):463-469

55 Brinkmann V, Zychlinsky A. Neutrophil extracellular traps: is immunity the second function of chromatin? J Cell Biol 2012;198 (05):773-783

56 Martinod K, Wagner DD. Thrombosis: tangled up in NETs. Blood 2014;123(18):2768-2776

57 Brinkmann V, Reichard U, Goosmann C, et al. Neutrophil extracellular traps kill bacteria. Science 2004;303(5663):1532-1535 
58 Massberg S, Grahl L, von Bruehl ML, et al. Reciprocal coupling of coagulation and innate immunity via neutrophil serine proteases. Nat Med 2010;16(08):887-896

$59 \mathrm{Xu}$ J, Zhang X, Pelayo R, et al. Extracellular histones are major mediators of death in sepsis. Nat Med 2009;15(11):1318-1321

60 Abrams ST, Zhang N, Manson J, et al. Circulating histones are mediators of trauma-associated lung injury. Am J Respir Crit Care Med 2013;187(02):160-169

61 Bosmann M, Grailer JJ, Ruemmler R, et al. Extracellular histones are essential effectors of C5aR- and C5L2-mediated tissue damage and inflammation in acute lung injury. FASEB J 2013; 27(12):5010-5021

62 Ekaney ML, Otto GP, Sossdorf M, et al. Impact of plasma histones in human sepsis and their contribution to cellular injury and inflammation. Crit Care 2014;18(05):543

63 Grailer JJ, Ward PA. Lung inflammation and damage induced by extracellular histones. Inflamm Cell Signal 2014;1(04):1

64 Xiang M, Fan J. Pattern recognition receptor-dependent mechanisms of acute lung injury. Mol Med 2010;16(1,2):69-82

65 Achouiti A, van der Meer AJ, Florquin S, et al. High-mobility group box 1 and the receptor for advanced glycation end products contribute to lung injury during Staphylococcus aureus pneumonia. Crit Care 2013;17(06):R296

66 Chouteau JM, Obiako B, Gorodnya OM, et al. Mitochondrial DNA integrity may be a determinant of endothelial barrier properties in oxidant-challenged rat lungs. Am J Physiol Lung Cell Mol Physiol 2011;301(06):L892-L898

67 Lee YL, King MB, Gonzalez RP, et al. Blood transfusion products contain mitochondrial DNA damage-associated molecular patterns: a potential effector of transfusion-related acute lung injury. J Surg Res 2014;191(02):286-289

68 Nakahira K, Kyung SY, Rogers AJ, et al. Circulating mitochondrial DNA in patients in the ICU as a marker of mortality: derivation and validation. PLoS Med 2013;10(12):e1001577, discussion e1001577

69 Simmons JD, Lee YL, Mulekar S, et al. Elevated levels of plasma mitochondrial DNA DAMPs are linked to clinical outcome in severely injured human subjects. Ann Surg 2013;258(04):591-596, discussion 596-598

70 Krychtiuk KA, Ruhittel S, Hohensinner PJ, et al. Mitochondrial DNA and toll-like receptor-9 are associated with mortality in critically ill patients. Crit Care Med 2015;43(12):2633-2641

71 Maitland K, Kiguli S, Opoka RO, et al; FEAST Trial Group. Mortality after fluid bolus in African children with severe infection. N Engl J Med 2011;364(26):2483-2495

72 Piastra M, De Luca D, Pietrini D, et al. Noninvasive pressuresupport ventilation in immunocompromised children with ARDS: a feasibility study. Intensive Care Med 2009;35(08): 1420-1427

73 Piastra M, De Luca D, Marzano L, et al. The number of failing organs predicts non-invasive ventilation failure in children with ALI/ARDS. Intensive Care Med 2011;37(09):1510-1516

74 Mayordomo-Colunga J, Pons M, López Y, et al. Predicting noninvasive ventilation failure in children from the $\mathrm{SpO}_{2} / \mathrm{FiO}_{2}(\mathrm{SF})$ ratio. Intensive Care Med 2013;39(06):1095-1103

75 Bernet V, Hug MI, Frey B. Predictive factors for the success of noninvasive mask ventilation in infants and children with acute respiratory failure. Pediatr Crit Care Med 2005;6(06):660-664

76 Pancera CF, Hayashi M, Fregnani JH, Negri EM, Deheinzelin D, de Camargo B. Noninvasive ventilation in immunocompromised pediatric patients: eight years of experience in a pediatric oncology intensive care unit. J Pediatr Hematol Oncol 2008;30 (07):533-538

77 Dohna-Schwake C, Stehling F, Tschiedel E, Wallot M, Mellies U. Non-invasive ventilation on a pediatric intensive care unit: feasibility, efficacy, and predictors of success. Pediatr Pulmonol 2011;46(11):1114-1120
78 Yañez LJ, Yunge M, Emilfork M, et al. A prospective, randomized, controlled trial of noninvasive ventilation in pediatric acute respiratory failure. Pediatr Crit Care Med 2008;9(05):484-489

79 Patel BK, Wolfe KS, Pohlman AS, Hall JB, Kress JP. Effect of noninvasive ventilation delivered by helmet vs face mask on the rate of endotracheal intubation in patients with acute respiratory distress syndrome: a randomized clinical trial. JAMA 2016;315 (22):2435-2441

80 Hutchings FA, Hilliard TN, Davis PJ. Heated humidified high-flow nasal cannula therapy in children. Arch Dis Child 2015;100(06): 571-575

81 Essouri S, Carroll C; Pediatric Acute Lung Injury Consensus Conference Group. Noninvasive support and ventilation for pediatric acute respiratory distress syndrome: proceedings from the Pediatric Acute Lung Injury Consensus Conference. Pediatr Crit Care Med 2015;16(05, Suppl 1):S102-S110

82 Messika J, Ben Ahmed K, Gaudry S, et al. Use of high-flow nasal cannula oxygen therapy in subjects with ards: a 1-year observational study. Respir Care 2015;60(02):162-169

83 Arnold JH, Hanson JH, Toro-Figuero LO, Gutiérrez J, Berens RJ, Anglin DL. Prospective, randomized comparison of high-frequency oscillatory ventilation and conventional mechanical ventilation in pediatric respiratory failure. Crit Care Med 1994;22(10):1530-1539

84 Curley MA, Hibberd PL, Fineman LD, et al. Effect of prone positioning on clinical outcomes in children with acute lung injury: a randomized controlled trial. JAMA 2005;294(02):229-237

85 Willson DF, Thomas NJ, Markovitz BP, et al; Pediatric Acute Lung Injury and Sepsis Investigators. Effect of exogenous surfactant (calfactant) in pediatric acute lung injury: a randomized controlled trial. JAMA 2005;293(04):470-476

86 Willson DF, Thomas NJ, Tamburro R, et al; Pediatric Acute Lung and Sepsis Investigators Network. Pediatric calfactant in acute respiratory distress syndrome trial. Pediatr Crit Care Med 2013; 14(07):657-665

87 Amato MB, Meade MO, Slutsky AS, et al. Driving pressure and survival in the acute respiratory distress syndrome. $\mathrm{N}$ Engl J Med 2015;372(08):747-755

88 de Jager P, Burgerhof JG, van Heerde M, Albers MJ, Markhorst DG, Kneyber MC. Tidal volume and mortality in mechanically ventilated children: a systematic review and meta-analysis of observational studies*. Crit Care Med 2014;42(12):2461-2472

89 Randolph AG. Management of acute lung injury and acute respiratory distress syndrome in children. Crit Care Med 2009; 37(08):2448-2454

90 Santschi M, Jouvet P, Leclerc F, et al; PALIVE Investigators; Pediatric Acute Lung Injury and Sepsis Investigators Network (PALISI); European Society of Pediatric and Neonatal Intensive Care (ESPNIC). Acute lung injury in children: therapeutic practice and feasibility of international clinical trials. Pediatr Crit Care Med 2010;11(06):681-689

91 Young D, Lamb SE, Shah S, et al; OSCAR Study Group. Highfrequency oscillation for acute respiratory distress syndrome. N Engl J Med 2013;368(09):806-813

92 Ferguson ND, Cook DJ, Guyatt GH, et al; OSCILLATE Trial Investigators; Canadian Critical Care Trials Group. High-frequency oscillation in early acute respiratory distress syndrome. $\mathrm{N}$ Engl J Med 2013;368(09):795-805

93 Rettig JS, Smallwood CD, Walsh BK, et al. High-frequency oscillatory ventilation in pediatric acute lung injury: a multicenter international experience. Crit Care Med 2015;43(12):2660-2667

94 Zabrocki LA, Brogan TV, Statler KD, Poss WB, Rollins MD, Bratton SL. Extracorporeal membrane oxygenation for pediatric respiratory failure: Survival and predictors of mortality. Crit Care Med 2011;39(02):364-370

95 Minneci PC, Kilbaugh TJ, Chandler HK, Behar BJ, Localio AR, Deans KJ. Factors associated with mortality in pediatric patients 
requiring extracorporeal life support for severe pneumonia. Pediatr Crit Care Med 2013;14(01):e26-e33

96 Gow KW, Wulkan ML, Heiss KF, et al. Extracorporeal membrane oxygenation for support of children after hematopoietic stem cell transplantation: the extracorporeal life support organization experience. J Pediatr Surg 2006;41(04):662-667

97 Gupta M, Shanley TP, Moler FW. Extracorporeal life support for severe respiratory failure in children with immune compromised conditions. Pediatr Crit Care Med 2008;9(04):380-385

98 Brogan TV, Zabrocki L, Thiagarajan RR, Rycus PT, Bratton SL. Prolonged extracorporeal membrane oxygenation for children with respiratory failure. Pediatr Crit Care Med 2012;13(04): e249-e254

99 MacLaren G, Butt W, Best D, Donath S. Central extracorporeal membrane oxygenation for refractory pediatric septic shock. Pediatr Crit Care Med 2011;12(02):133-136

100 Combes A, Hajage D, Capellier G, et al; EOLIA Trial Group, REVA, and ECMONet. Extracorporeal membrane oxygenation for severe acute respiratory distress syndrome. $\mathrm{N}$ Engl J Med 2018;378(21): 1965-1975

101 Freeman CL, Bennett TD, Casper TC, et al. Pediatric and neonatal extracorporeal membrane oxygenation: does center volume impact mortality?* Crit Care Med 2014;42(03):512-519

102 Annane D, Sébille V, Charpentier C, et al. Effect of treatment with low doses of hydrocortisone and fludrocortisone on mortality in patients with septic shock. JAMA 2002;288(07):862-871

103 Sprung CL, Annane D, Keh D, et al; CORTICUS Study Group. Hydrocortisone therapy for patients with septic shock. N Engl J Med 2008;358(02):111-124

104 Zimmerman JJ, Williams MD. Adjunctive corticosteroid therapy in pediatric severe sepsis: observations from the RESOLVE study. Pediatr Crit Care Med 2011;12(01):2-8
105 Wong HR, Cvijanovich NZ, Anas N, et al. Developing a clinically feasible personalized medicine approach to pediatric septic shock. Am J Respir Crit Care Med 2015;191(03):309-315

106 Markovitz BP, Goodman DM, Watson RS, Bertoch D, Zimmerman J. A retrospective cohort study of prognostic factors associated with outcome in pediatric severe sepsis: what is the role of steroids? Pediatr Crit Care Med 2005;6(03):270-274

107 Atkinson SJ, Cvijanovich NZ, Thomas NJ, et al. Corticosteroids and pediatric septic shock outcomes: a risk stratified analysis. PLoS One 2014;9(11):e112702

108 Menon K, McNally JD, Choong K, et al; Canadian Critical Care Trials Group STRIPES Investigators. A cohort study of pediatric shock: frequency of corticosteriod use and association with clinical outcomes. Shock 2015;44(05):402-409

109 Yehya N, Servaes S, Thomas NJ, Nadkarni VM, Srinivasan V. Corticosteroid exposure in pediatric acute respiratory distress syndrome. Intensive Care Med 2015;41(09):1658-1666

110 Drago BB, Kimura D, Rovnaghi CR, et al. Double-blind, placebocontrolled pilot randomized trial of methylprednisolone infusion in pediatric acute respiratory distress syndrome. Pediatr Crit Care Med 2015;16(03):e74-e81

111 Yehya N, Vogiatzi MG, Thomas NJ, Srinivasan V. Cortisol correlates with severity of illness and poorly reflects adrenal function in pediatric acute respiratory distress syndrome. J Pediatr 2016; 177:212-218.e1

112 Boonen E, Vervenne H, Meersseman P, et al. Reduced cortisol metabolism during critical illness. N Engl J Med 2013;368(16): 1477-1488

113 Meduri GU, Headley AS, Golden E, et al. Effect of prolonged methylprednisolone therapy in unresolving acute respiratory distress syndrome: a randomized controlled trial. JAMA 1998; 280(02):159-165 